\title{
INTERNET NO ENSINO
}

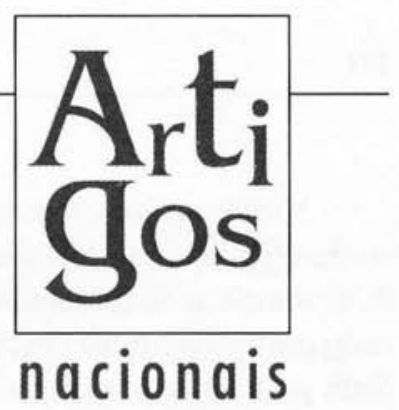

\section{Uso da Internet no ensino transforma o papel do professor, exigindo dele maior atenção para orientação e acompanhamento do aluno}

A Internet pode tornar-se uma mídia poderosa para o ensino de Comunicação, tanto para os professores como para os alunos. Atualmente consegue integrar texto, imagem e som a um custo barato, com rapidez, flexibilidade e interação até há pouco tempo impossíveis. Há uma clara aproximação da televisão, do computador e da Internet. A tela em que trabalhamos e vemos televisão (Netputer ou WebTV) aproxima áreas tecnológicas que até agora estavam separadas. A chegada da Internet à TV a cabo, sem dúvida, é um marco decisivo para visualizar imagens em movimento e sons, integrando o audiovisual, a hipermídia (combinação de hipertexto e multimídia, portanto, um sistema de obtenção de informação que provê acesso a textos, gravações de áudio e vídeo, fotografias e gráficos), o texto linkado (palavra ou ícone destacado em um texto que remete a uma conexão com outra informação em outro texto) e a narrativa do cinema e da TV.

A educação presencial pode modificar-se significativamente com as redes eletrônicas. As universidades se abrem para o mundo, professores e alunos começam a intercomunicar-se, a trocar informações, a participar de pesquisas, de projetos em conjunto. A educação continuada é facilitada pela possibilidade de integração de várias mídias, acessando-as tanto em tempo real como assincronicamente, isto é, no horário favorável a cada indivíduo, facilitando o contato entre educadores e educandos.

$\mathrm{Na}$ Internet encontramos vários tipos de aplicações educacionais: de divulgação, de pesquisa, de apoio ao ensino e de comunicação. A divulgação pode ser institucional - a escola mostra o que faz - ou particular - grupos, professores ou alunos criam suas homepages pessoais, com o que produzem de mais significativo. A pesquisa pode ser feita individualmente ou em grupo: ao vivo - durante a aula - ou fora da aula; pode ser uma atividade obrigatória ou livre. Nas atividades de apoio ao ensino, podemos conseguir textos, imagens, sons do tema específico do programa, utilizando-os como um elemento a mais, junto com livros, revistas e vídeos. A comunicação se dá entre professores e alunos, entre professores e professores, entre alunos e outros colegas da mesma ou de outras cidades e países. A comunicação se dá com pessoas conhecidas e desconhecidas, próximas e distantes, interagindo esporádica ou sistematicamente.

\section{O AUTOR}

\section{José Manuel Morán}

Doutor em Comunicação pela Universidade de São Paulo. Professor de Novas Tecnologias no Curso de Televisão da ECA-USP. e-mail: jmmoran@usp.br 
Neste artigo vou concentrar-me em como utilizar a Internet no ensino presencial de Comunicação, no ensino que está organizado para o encontro físico em salas de aula. Nele podemos introduzir formas de pesquisa e comunicação não presenciais, que nos ajudarão a renovar a forma de dar aula, de investigar, de relacionar-nos dentro e fora da sala de aula.

\section{EXPERIÊNCIAS PESSOAIS COM ENSINO NA INTERNET}

Venho desenvolvendo algumas experiências no ensino de graduação e de pósgraduação na Escola de Comunicações e Artes da Universidade de São Paulo. Criei uma página pessoal na Internet, com dois endereços: http://www.eca.usp.br/eca/prof/ moran/mor.htm e http://www.geocities.com/ TelevisionCity/7815/index.html. Nelas constam as disciplinas de pós-graduação: Redes eletrônicas na Educação e Novas Tecnologias para uma Nova Educação; e três de graduação: Novas Fronteiras da Televisão, Legislação e Ética do Radialismo e Mercadologia de Rádio e Televisão - com o programa e alguns textos meus e de meus alunos. O roteiro básico é o seguinte. No começo do semestre, cada aluno escolhe um assunto específico dentro da matéria, vai pesquisando-o na Internet e na biblioteca. Ao mesmo tempo, pesquisamos também temas básicos do curso. O aluno apresenta os resultados da sua pesquisa específica na classe e depois pode divulgá-los, se quiser, através da Internet.

Disponho de duas salas de aula com dez computadores em uma e quatorze em outra, ligados à Internet por fibra ótica, para vinte alunos, em média. Utilizamos essa sala a cada duas ou três semanas. As outras aulas acontecem na sala convencional.
$\mathrm{O}$ fato de ver o seu nome na Internet $\mathrm{e}$ a possibilidade de divulgar os seus trabalhos e pesquisas exercem uma forte motivação nos alunos, estimulando-os a participar mais em todas as atividades do curso. Enquanto preparam os trabalhos pessoais, vou desenvolvendo com eles algumas atividades.

Começamos com uma aula introdutória para os que não estão familiarizados com a Internet. Nela aprendemos a conhecer e a usar as principais ferramentas. Fazemos pesquisa livre, em vários programas de busca. Cadastramos cada aluno para que tenha seu e-mail pessoal (na própria Universidade ou em sites que oferecem endereços eletrônicos gratuitamente).

Num segundo momento, todos pesquisamos o mesmo tópico do curso nos programas de busca (como Altavista, Yahoo, Lycos, Infossek, Galaxy, Cadê). Eles vão gravando endereços, artigos, imagens mais interessantes em disquete e também fazem anotações escritas, com rápidos comentários sobre o que estão salvando. As descobertas mais importantes são comunicadas aos colegas. Os resultados são socializados, discutidos, comparados.

O papel do professor é o de acompanhar cada aluno, incentivá-lo, resolver suas dúvidas, divulgar as melhores descobertas. No fim da aula, fazemos um rápido balanço e peço que sintetizem o que foi mais importante e que estudem com mais calma o material gravado, para descobrir as principais coincidências e divergências no material encontrado.

$\mathrm{Na}$ aula seguinte esse material é trocado, discutido junto com outros textos - revistas, livros e material da própria Internet trazidos pelo professor. As aulas com pesquisa na Internet se alternam com as aulas habituais. Posteriormente, cada aluno de- 
senvolve o seu tema específico de pesquisa, sob minha supervisão. Estou junto com eles, dando dicas, tirando dúvidas, anotando descobertas. Esses temas específicos são mais tarde apresentados em classe para os colegas. O professor complementa, questiona, relaciona essas apresentações com a matéria como um todo. Alguns alunos criam suas páginas pessoais e outros entregam somente os resultados das suas pesquisas para colocá-los na minha página.

Além das aulas, acontece um estimulante processo de comunicação virtual, junto com o presencial. Eles podem pesquisar em uma sala especial em qualquer horário, se houver máquinas livres. Os alunos me procuram mais para atendimento específico na minha sala, e também enviam mensagens eletrônicas. Como todos têm e-mail, de vez em quando envio sugestões pela rede, lembro-os de datas de leituras de textos. Estou começando a enviar alguns artigos pela própria rede. Na pós-graduação estou fazendo algumas experiências de discussões virtuais com programas em tempo real, escrevendo ao mesmo tempo (programas IRC - Internet Relay Chat, como o Mirc). Neste momento também estamos começando a experimentar programas de som e de imagem, interagindo com outras pessoas, fora da Universidade, em tempo real, discutindo assuntos da matéria.

Adapto esse processo também aos meus orientandos de graduação (trabalhos de conclusão de curso), de mestrado e doutorado. Os que não moram em São Paulo se comunicam com mais freqüência comigo pela Internet, enviam-me capítulos das suas teses eletronicamente e eu os devolvo da mesma forma. Aqueles que já terminaram têm uma página na rede com o resumo da tese e outras informações que julguem convenientes.
Ensinar utilizando a Internet exige uma forte dose de atenção do professor. Diante de tantas possibilidades de busca, a própria navegação se torna mais sedutora do que o necessário trabalho de interpretação. Os alunos tendem a dispersar-se diante de tantas conexões possíveis e de endereços dentro de outros endereços, de imagens e textos que se sucedem ininterruptamente. Tendem a acumular muitos textos, lugares, idéias, que ficam gravados, impressos, anotados. Colocam os dados em seqüência mais do que em confronto. Copiam os endereços, os artigos uns ao lado dos outros, sem a devida triagem.

Creio que isso se deve a uma primeira etapa de deslumbramento diante de tantas possibilidades que a Internet oferece. É mais atraente navegar, descobrir coisas novas do que analisá-las, compará-las, separando o que é essencial do acidental, hierarquizando idéias, assinalando coincidências e divergências. Por outro lado, isso reforça uma atitude consumista dos jovens diante da produção cultural audiovisual. Ver equivale, na cabeça de muitos, a compreender. Há um certo ver superficial, rápido, guloso sem o devido tempo de reflexão, de aprofundamento, de cotejamento com outras leituras. Os alunos se impressionam primeiro com as páginas mais bonitas, que exibem mais imagens, animações, sons. As imagens animadas exercem um fascínio semelhante às do cinema, vídeo e televisão. Os lugares menos atraentes visualmente costumam ser deixados em segundo plano, o que acarreta, às vezes, perda de informações de grande valor.

É importante que o professor fique atento ao ritmo de cada aluno, às suas formas pessoais de navegação. $\mathrm{O}$ professor não impõe; acompanha, sugere, incentiva, questiona, aprende junto com o aluno. 
Ensinar utilizando a Internet pressupõe uma atitude do professor diferente da convencional. $O$ professor não é $o$ informador, aquele que centraliza a informação. A informação está em inúmeros bancos de dados, em revistas, livros, textos, endereços de todo o mundo. $O$ professor é o coordenador do processo, o responsável na sala de aula. Sua primeira tarefa é sensibilizar os alunos, motivá-los para a importância da matéria, mostrando entusiasmo, ligação da matéria com os interesses dos alunos, com a totalidade da habilitação escolhida.

A Internet é uma tecnologia que facilita a motivação dos alunos pela novidade e pelas possibilidades inesgotáveis de pesquisa que oferece. Essa motivaçã̀o aumenta se o professor a faz em um clima de confiança, de abertura, de cordialidade com os alunos. Mais que a tecnologia, a comunicação autêntica do professor estabelece relações de confiança com os seus alunos, pelo equilíbrio, competência e simpatia com que atua.

\section{PESQUISA NA INTERNET}

A Internet está trazendo inúmeras possibilidades de pesquisa para professores e alunos, dentro e fora da sala de aula. Digitando-se duas ou três palavras nos serviços de busca, encontram-se múltiplas respostas para qualquer tema. É uma facilidade deslumbrante, impossível de ser imaginada há bem pouco tempo. Isso traz grandes vantagens e também alguns problemas ${ }^{1}$.

Podemos partir, na pesquisa, do geral para o específico, dos grandes tópicos para os subtópicos. Num primeiro momento pro- curamos nos programas de busca as palavras-chave mais abrangentes, mais amplas. Por exemplo, televisão, televisão e educação. As palavras podem ser buscadas em serviços norte-americanos como o Altavista, digitando-as, além do inglês, em português ou em espanhol, o que apontará os endereços predominantemente nessas línguas. As primeiras buscas mostrarão milhares de resultados. Escolheremos alguns das primeiras páginas. Gravamos alguns endereços, anotamos por escrito também as observações principais. $\mathrm{O}$ estudante iniciante na Internet se deixa, primeiro, deslumbrar quando vê que uma pesquisa apresenta cem mil resultados. Depois desanima, ao constatar que não pode esgotá-la, que há inúmeras repetições, muitas indicações equivocadas. Convém procurar em mais de um programa de busca, porque os resultados não são idênticos.

Num segundo momento, dirigimos mais a busca para temas específicos: exemplo, televisão por cabo, televisão de acesso público, televisão comunitária, televisão interativa. Fazemos essa pesquisa em vários programas de busca. Vamos abrindo alguns endereços. Com a prática desenvolvemos a habilidade de descobrir onde estão os melhores endereços, os que valem a pena aprofundar. Pesquisamos observando a organização dos tópicos, a riqueza e a variedade de artigos, a respeitabilidade da instituição e dos pesquisadores.

Podemos coordenar pesquisas com objetivos bem específicos, monitorando de perto cada etapa da busca, pedindo que anotem os dados mais importantes, e que reconstruam ao final os resultados. É importante sensibilizar o aluno antes para o que se quer conseguir neste momento, neste tópico. Se o aluno tem claro ou encontra valor 
no que vai pesquisar, o fará com mais rapidez e eficiência. O professor precisa estar atento, porque a tendência na Internet é para a dispersão fácil. $\mathrm{O}$ intercâmbio constante de resultados e a supervisão do professor podem ajudar a obter melhores resultados.

$\mathrm{Na}$ pesquisa com objetivos bem específicos podemos fazer uma busca uniforme, isto é, todos pesquisam os mesmos endereços previamente indicados pelo professor ou fazem uma busca mais aberta sobre o mesmo assunto. Vale a pena alternar as duas formas. Na primeira há menos variedade de lugares pesquisados, mas podemos obter resultados mais aprofundados. Na segunda, ao deixar menos definidos os lugares e nos fixarmos no tema, as possibilidades de encontrar resultados inesperados aumentam.

Podemos fazer pesquisas de temas diferentes, individualmente ou em pequenos grupos. É interessante que os alunos escolham algum assunto dentro do programa, algo mais próximo do interesse deles e que eles valorizam mais. Essas pesquisas podem ser realizadas dentro e fora do período de aula. Durante a aula, o professor acompanha cada aluno, tira dúvidas, dá sugestões, incentiva, complementa os resultados, aprende com as informações que os alunos passam. Essas pesquisas são depois apresentadas para os demais colegas e para o professor. Cabe ao professor complementar, problematizar, adaptar à realidade local os resultados trazidos pelos alunos.

Como há tantas possibilidades de pesquisa e facilidade de dispersão, o educador estará atento, na aula-pesquisa, a escolher o melhor momento para que cada aluno apresente os resultados de seu trabalho para a classe. A comunicação de resultados pode ser espontânea: o professor pede que, quando alguém encontre algo significativo, o comunique a todos. Isso ajuda aos colegas avançarem mais, aprofundarem-se na pesquisa dos mesmos assuntos nos melhores sites.

Pode-se também, ao final do período da aula-pesquisa, pedir aos alunos que relatem a síntese do que encontraram de mais significativo. Os alunos terão gravadas as principais páginas, junto com um roteiro de anotações, para esclarecer, ao final, a navegação feita e onde foram encontradas as me-

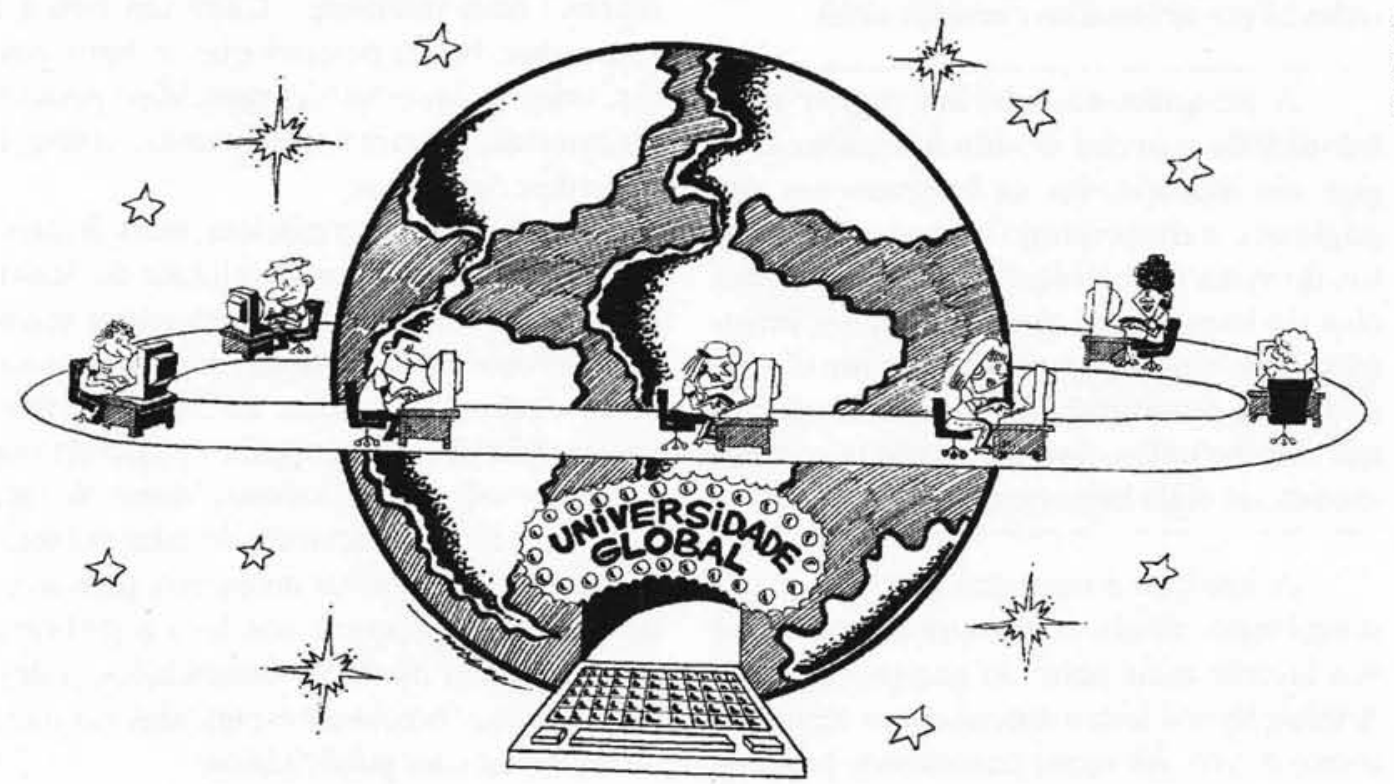


lhores relações. Um aprofundamento dos resultados pesquisados pode ser deixado para a próxima aula. Os alunos fazem, fora da aula, a análise das páginas encontradas. Procuram o que houve de mais significativo. Esses dados são disponibilizados para todos na aula seguinte. Professor e alunos relacionam as coincidências e divergências entre os resultados encontrados e as informações já conhecidas em reflexões anteriores, em livros e revistas. Essa discussão maior é importante para que a Internet não se torne só uma bela diversão e que esse tempo de pesquisa se multiplique com a difusão em comum, pela troca, pela discussão e síntese final. A comunicação dos resultados ao grupo é cada vez mais relevante pela quantidade, variedade, desigualdade de dados e informações contidas nas páginas da Internet. Há muitos pontos de vista diferentes explicitados. A disponibilização em comum facilita a comparação, a seleção, a organização hierárquica de idéias, conceitos, valores. A tendência dos alunos é de quantificar, mais do que analisar. Juntam inúmeras páginas, mas se não estivermos atentos, não explorarão todas as possibilidades contidas nelas.

A pesquisa na Internet requer uma habilidade especial devido à rapidez com que são modificadas as informações nas páginas e a diversidade de pessoas e pontos de vista envolvidos. A navegação precisa de bom senso, gosto estético e intuição. Bom senso para não se deter diante de tantas possibilidades, sabendo selecionar dentre todas elas, em rápidas comparações, as mais importantes.

A intuição é um radar que vamos desenvolvendo de clicar o mouse nos links que nos levarão mais perto do que procuramos. A intuição nos leva a aprender por tentativa, acerto e erro. Às vezes passaremos bastante tempo sem achar algo importante e, de repente, se estivermos atentos, conseguiremos um artigo fundamental, uma página esclarecedora. O gosto estético nos ajuda a reconhecer e apreciar páginas elaboradas com cuidado, com bom gosto, com integração de imagem e texto. Principalmente para os alunos, o estético é uma qualidade fundamental de atração. Uma página bem apresentada, com recursos atraentes, é imediatamente selecionada e pesquisada.

Acontece com freqüência encontrar assuntos novos, sites diferentes dos buscados e que também podem interessar a alguém em particular. $\mathrm{O}$ educador não deve simplesmente dizer ao aluno que aquele assunto não faz parte da aula. Pode pedir-lhe que grave rapidamente o que achar mais importante e que deixe para outro momento o aprofundamento desse novo assunto, para voltar logo mais ao tema específico da aula.

\section{COMUNICAÇÃO NA INTERNET}

Todos procuram na rede seus semelhantes, seus interesses. Cada um busca a sua turma, busca pessoas que tenham gostos, valores, expectativas parecidas; pessoas fisicamente próximas e distantes, conhecidas e desconhecidas.

Uma das características mais interessantes da Internet é a possibilidade de descobrir lugares inesperados, de encontrar materiais valiosos, endereços curiosos, programas úteis, pessoas divertidas, informações relevantes. São tantas as conexões possíveis que a viagem vale por si mesma. Viajar na rede precisa de intuição acurada, de estar preparado para fazer tentativas no escuro, para acertar e errar. A pesquisa nos leva a garimpar jóias entre um monte de banalidades, a descobrir pedras preciosas escondidas no meio de inúmeros sites publicitários. 
A comunicação torna-se mais e mais sensorial, mais e mais multidimensional, mais e mais não linear. As técnicas de apresentação são mais fáceis hoje e mais atraentes do que anos atrás, o que aumenta o padrão de exigência para mostrar qualquer trabalho através de sistemas multimídia. $\mathrm{O}$ som não será um acessório, mas uma parte integral da narrativa. $\mathrm{O}$ texto na tela aumentará de importância, pela sua maleabilidade, facilidade de correção, de cópia, de deslocamento e de transmissão.

$\mathrm{Na}$ educação, professores e alunos praticam formas de comunicação novas. Encontram colegas com os quais podem comunicar-se facilmente por correio eletrônico, por listas de discussão, por comunicação instantânea em IRC. Atualmente começa a comunicar-se através de voz (programas como o Iphone) e também de imagem (programas como o CuSeeme ou a última versão do Iphone).

Aumenta a procura pelos chats ou bate-papos. Muitos estudantes passam horas seguidas em conversas aleatórias, fragmentadas, num autêntico jogo de cena, de camuflagem de identidades, de meias-verdades. Mas o chat tem um grande potencial democrático, por ser aberto, multidimensional. Nessas trocas acontecem encontros virtuais, criam-se amizades, relacionamentos inesperados que começam virtualmente e muitas vezes levam a contatos presenciais.

Começamos a ser nossos próprios editores de textos e diretores de imagens na Internet. Há centenas de jornais escolares na rede. Quem tem algo a dizer pode fazê-lo sem depender da autorização de emissoras, jornais ou conselhos editoriais; basta colocá-lo na sua página pessoal. Os estudantes podem mostrar sua capacidade on line, ao vivo, sem ter que esperar anos pelo ingresso formal dentro do mercado de trabalho. $\mathrm{O}$ ar- tista está podendo divulgar suas obras para o mundo inteiro imediatamente. $\mathrm{O}$ pesquisador consegue publicar na rede os resultados do seu trabalho instantaneamente, sem depender do julgamento de especialistas e sem demora na publicação. Isso torna mais difícil a seleção do que vale ou não vale a pena ser lido. Nem sempre há um conselho editorial de notáveis para filtrar os melhores artigos. Com isso há muito lixo cultural, mas também se amplia imensamente o número e a variedade de pessoas que se expõem ao julgamento público.

As profissões ligadas à informação $\mathrm{e}$ à comunicação estão experimentando um grande desenvolvimento. Cada vez temos menos tempo para procurar as informações necessárias. Por isso precisamos de mediadores, de pessoas que saibam escolher o que é mais importante para cada um de nós em todas as áreas da nossa vida, que garimpem o essencial, que nos orientem sobre as suas consequiências, que traduzam os dados técnicos em linguagem acessível e contextualizada.

\section{AVALIAÇÃO DO USO DA INTERNET}

Nos projetos brasileiros que temos acompanhado, podemos observar algumas dimensões positivas e alguns problemas. Aumenta a motivação, o interesse dos alunos pelas aulas, pela pesquisa, pelos projetos. Motivação ligada à curiosidade pelas novas possibilidades, à modernidade que representa a Internet. Há uma primeira etapa de deslumbramento, de curiosidade, de fascínio diante de tantas possibilidades novas. Depois vem a etapa de domínio da tecnologia, de escolha das preferências. Mais tarde, começa-se a enxergar os defeitos, os problemas, as dificuldades de conexão, as repetições, a demora. 
Comparando as minhas aulas agora e antes da Internet, posso afirmar que aumentou significativamente a motivação, $o$ interesse e a comunicação com os alunos e a deles entre si. Estão mais abertos, confiantes. Intercambiamos mais materiais, sugestões, dúvidas. Trazem-me muitas novidades. Já me aconteceu de em alguns seminários apresentarem resultados com informações que eu desconhecia sobre tópicos do meu programa, por estarem extremamente atualizadas, o que traz novas perspectivas para a matéria.

$\mathrm{O}$ aluno aumenta as conexões lingüísticas, as geográficas e as interpessoais. As lingüísticas, porque interage com inúmeros textos, imagens, narrativas, formas coloquiais e formas elaboradas. Com textos sisudos e textos populares. As geográficas, porque se desloca continuamente em diferentes espaços, culturas, tempos e adquire uma visão mais ecológica sobre os problemas da cidade. As interpessoais, porque se comunica e conhece pessoas próximas e distantes, da sua idade e de outras, on line e off line.

$\mathrm{O}$ aluno desenvolve a aprendizagem cooperativa, a pesquisa em grupo, a troca de resultados. A interação bem-sucedida aumenta a aprendizagem. Em alguns casos há uma competição excessiva, monopólio de determinados alunos sobre o grupo. Mas, no conjunto, a cooperação prevalece.

A Internet ajuda a desenvolver a intuição, a flexibilidade mental, a adaptação a ritmos diferentes. A intuição, porque as informações vão sendo descobertas por acerto e erro, por conexões escondidas. As conexões não são lineares, vão linkando-se por hipertextos, textos interconectados, mas ocultos, com inúmeras possibilidades diferentes de navegação. Desenvolve a flexibilidade, porque a maior parte das seqüências são imprevisíveis, abertas. A mesma pessoa costuma ter dificuldades em refazer a mes- ma navegação duas vezes. Ajuda na adaptação a ritmos diferentes: a Internet permite a pesquisa individual, em que cada aluno vai no seu próprio ritmo, e a pesquisa em grupo, em que se desenvolve a aprendizagem colaborativa.

Na Internet também desenvolvemos formas novas de comunicação, principalmente escrita. Escrevemos de forma mais aberta, hipertextual, conectada, multilingüística, aproximando texto e imagem. Agora começamos a incorporar sons e imagens em movimento.

A possibilidade de divulgar páginas pessoais e grupais na Internet gera uma grande motivação, visibilidade, responsabilidade para professores e alunos. Todos se esforçam por escrever bem, por comunicar melhor as suas idéias, para serem bem aceitos, para não fazer feio. Alguns dos endereços mais interessantes ou visitados da Internet no Brasil são feitos por adolescentes ou jovens.

$\mathrm{O}$ interesse pelo estudo de línguas aumenta. A aprendizagem de línguas, principalmente do inglês, é um dos motivos principais para o sucesso dos projetos. Os alunos enviam e recebem mensagens, o que exige uma boa fluência em língua estrangeira. Com programas de comunicação na Internet em tempo real, a necessidade do domínio de línguas estrangeiras é mais percebido. Em programas de IRC, de audiofone (como o Iphone), de videoconferência, os alunos escrevem ou falam ao vivo, com rapidez.

Outro resultado comum à maior parte dos projetos na Internet confirma a riqueza de interações que surgem, os contatos virtuais, as amizades, as trocas constantes com outros colegas, tanto por parte de professores como dos alunos. Os contatos virtuais se 
transformam, quando é possível, em presenciais. A comunicação afetiva, a criação de amigos em diferentes países se transforma em um grande resultado individual e coletivo dos projetos.

\section{ALGUNS PROBLEMAS}

Criam-se todos os dias mais de 140 mil novas páginas de informações e serviços na rede. Há informações demais e conhecimento de menos no uso da Internet na educação. E há uma certa confusão entre informação e conhecimento.

Temos muitos dados, muitas informações disponíveis. $\mathrm{Na}$ informação organizamos os dados dentro de uma lógica, de um código, de uma estrutura determinada. Conhecer é integrar a informação no nosso referencial, no nosso paradigma, apropriandonos dela, tornando-a significativa para nós. O conhecimento não se passa, o conhecimento se cria, se constrói.

Há facilidade de dispersão. Muitos alunos se perdem no emaranhado de possibilidades de navegação. Não procuram o que está combinado, deixando-se arrastar para áreas de interesse pessoal. É fácil perder tempo com informações pouco significativas, ficando na periferia dos assuntos, sem aprofundá-los, sem integrá-los num paradigma consistente. Conhecer se dá ao filtrar, selecionar, comparar, avaliar, sintetizar, contextualizar o que é mais relevante e significativo.

Existem informações que distraem, que pouco acrescentam ao que já sabemos, mas que ocupam muito tempo de navegação. Perde-se muito tempo na rede. Mais se percebe essa perda de tempo ao observarmos a variedade de listas de discussão, os newsgroups, sobre qualquer tipo de assunto banal. Mas, em contrapartida, a Internet es- pelha nestas listas os desejos reais de cada um de nós, sem o controle do Estado ou de outras instituições, o que em outras mídias não acontece, pois sempre estão orientando-nos, oferecendo-nos os melhores produtos econômicos e culturais.

Impaciência de muitos alunos por mudar de um endereço para outro. Essa impaciência os leva a aprofundar pouco as possibilidades que há em cada página encontrada. Os alunos, principalmente os mais jovens, passeiam pelas páginas da Internet, descobrindo muitas coisas interessantes, enquanto deixam por afobação outras tantas, tão ou mais importantes, de lado.

É difícil avaliar rapidamente o valor de cada página, porque há muita semelhança estética na sua apresentação, há muita cópia da forma e do conteúdo: copiam-se os mesmos sites, os mesmos gráficos, animações, links.

Conciliar os diferentes tempos dos alunos. Uns respondem imediatamente. Outros demoram mais, são mais lentos. A lentidão pode permitir um maior aprofundamento. Na pesquisa individual esses ritmos diferentes podem ser respeitados. Nos projetos de grupo, depende muito da forma de coordenar e do respeito entre seus membros.

\section{INTERNET E NOVO PARADIGMA EDUCACIONAL}

Ensinar na e com a Internet atinge resultados significativos quando se está integrado em um contexto estrutural de mudança do processo de ensino-aprendizagem, no qual professores e alunos vivenciam formas de comunicação abertas, de participação interpessoal e grupal efetivas. Caso contrário, a Internet será uma tecnologia a mais, que reforçará as formas tradicionais de ensino. A Internet sozinha não modifica o processo 
de ensinar e aprender, mas modifica a atitude básica pessoal e institucional diante da vida, do mundo, de si mesmo e do outro.

A palavra-chave é integrar. Integrar a Internet com as outras tecnologias na educação - vídeo, televisão, jornal, computador. Integrar o mais avançado com as técnicas convencionais, integrar o humano e o tecnológico, dentro de uma visão pedagógica nova, criativa, aberta.

Há um pouco de confusão entre tecnologias interativas - que permitem participação - e processos interativos. Uma tecnologia pode ser profundamente interativa, como por exemplo o telefone, que permite o intercâmbio constante entre quem fala e quem responde. Isso não significa que automaticamente a comunicação entre pessoas pelo telefone seja interativa no sentido profundo. As pessoas podem manter formas de interação autoritárias, dependentes, contraditórias, abertas. O telefone facilita a troca, não a realiza sempre. Isso depende das pessoas envolvidas.

A mesma situação acontece com a Internet. Fala-se das inúmeras possibilidades de interação, de troca, de pesquisa. Elas

Resumo: $\mathrm{O}$ artigo relata e analisa trabalho didático utilizando a Internet em cursos de Comunicação, como instrumento de pesquisa, apoio ao ensino e como intercâmbio. Avalia os avanços e problemas que estão acontecendo atualmente e mostra que a Internet é mais eficaz quando está inserida em processos de ensino-aprendizagem de comunicação inovadores e participativos.

Palavras-chave: Internet, pesquisa, ensino de Comunicação, novas tecnologias existem. Mas, na prática, se uma escola mantém um projeto educacional autoritário, controlador, a Internet não irá modificar o processo já instalado. A Internet será uma ferramenta a mais que reforçará o autoritarismo existente: a escola fará tudo para controlar o processo de pesquisa dos alunos, os resultados esperados, a forma impositiva de avaliação.

Faremos com as tecnologias mais avançadas o mesmo que fazemos conosco, com os outros, com a vida. Se somos pessoas abertas, utilizaremos as tecnologias para comunicar-nos mais, para interagir melhor. Se somos pessoas fechadas, desconfiadas, utilizaremos as tecnologias de forma defensiva, superficial. Se somos pessoas autoritárias, utilizaremos as tecnologias para controlar, para aumentar o nosso poder. O poder de interação não está fundamentalmente nas tecnologias, mas nas nossas mentes.

Ensinar com a Internet será uma revolução, se mudarmos simultaneamente os paradigmas educacionais. Caso contrário, servirá somente como um verniz, um paliativo ou uma jogada de marketing. As profissões fundamentais dos próximos anos serão as ligadas à educação, à informação e à comunicação.

Abstract: The article reports on and analyzes didactic work using the Internet in Communications courses as a research instrument, teaching support mechanism, and for information exchange. It evaluates the advancements and problems that are currently taking place and reveals that the Internet is most effective when it is inserted in innovative and participative communications teaching and learning processes.

Key words: Internet, research, Communications teaching, new technologies 